\title{
ADESÃO DA UERN AO ENEM E A DEMOCRATIZAÇÃO DO ACESSO AO ENSINO SUPERIOR
}

\author{
J. M. C. T. SANTOS, M. K. SILVA, S. F. MELO \\ Universidade do Estado do Rio Grande do Norte \\ maccolle@hotmail.com
}

Submetido 11/03/2017 - Aceito 24/07/2017

DOI: $10.15628 /$ holos.2017.5777

\section{RESUMO}

O presente estudo tem como objetivo perceber os processos de democratização do acesso à educação superior na UERN, pela facilitação, expansão e universalização do acesso aos cursos de graduação por ela oferecidos. Nesse contexto, perscrutamos os ganhos que a adesão ao Enem/Sisu pela UERN representa para o acesso ao ensino superior na Instituição. Os dados aqui organizados, possibilitadores da discussão a respeito da democratização do acesso ao ensino superior, advieram da pesquisa bibliográfica. Ademais, os dados sobre o Enem, o Sisu e o processo de adesão da universidade, dentre outros, foram obtidos de pesquisas a notícias e reportagens veiculadas no portal do INEP, do SISU, do ENEM e da UERN, principalmente.

PALAVRAS-CHAVE: ENEM, SISU, Democratização, Ensino Superior.

\section{ACCESSION OF THE UERN TO THE ENEM AND THE DEMOCRATIZATION OF ACCESS TO HIGHER EDUCATION}

\begin{abstract}
The present study aims to understand the processes of democratization of access to higher education at UERN, by facilitating, expanding and universalizing access to undergraduate courses offered by it. In this context, we look at the gains that the adhesion to Enem/Sisu by UERN represents for the access to higher education in the Institution. The data organized here, which enabled
\end{abstract}

the discussion about the democratization of access to higher education, came from bibliographical research. In addition, the data on Enem, Sisu and the university's adhesion process, among others, were obtained from searches for news and reports on the INEP portal, SISU, ENEM and UERN, mainly.

KEYWORDS: ENEM, SISU, Democratization, Higher education. 


\section{INTRODUÇÃO}

As instituições de educação superior têm autonomia para deliberar sobre critérios e normas de seleção e admissão de seus alunos. O processo seletivo deve seguir todos os ditames da transparência, razão pela qual, nos termos do § 1ㅇ do artigo 44 da Lei de Diretrizes e Bases da Educação (LDB), seu resultado precisa ser tornado público pelas instituições de ensino superior que promove, sendo obrigatória a divulgação da relação nominal dos classificados, a respectiva ordem de classificação, bem como do cronograma das chamadas para matrícula, de acordo com os critérios para preenchimento das vagas constantes do respectivo edital (BRASIL, 1996).

As Instituições de Ensino Superior (IES), ao definirem os critérios a serem observados na seleção e admissão de estudantes, devem levar em conta os efeitos desses critérios sobre a orientação do ensino médio (artigo 51 da LDB). Contudo, com base no permissivo legal supracitado, pelo qual as instituições de educação superior tinham autonomia para deliberar sobre critérios e normas de seleção e admissão de seus alunos, o fim da obrigatoriedade do vestibular levou à multiplicidade de novas formas de seleção de candidatos às vagas nas universidades, que, na prática, pela pluralidade admitida, não garantiam, necessariamente, a democratização do processo de seleção de alunos.

A porta de entrada para a educação superior, nos termos da LDB, estava sendo, pois, utilizada para admitir aceitação de cartas de recomendação de empresas, reservas de vagas para alunos de colégios conveniados, 'vestibulinhos' pré-agendados, entre outras inovações, que nem sempre garantem os princípios de legalidade, moralidade, igualdade, transparência, dentre outros. Todo esse contexto de irregularidade na forma de seleção e admissão de alunos no ensino superior fez com que o Exame Nacional do Ensino Médio (Enem), em 1998, aparecesse como a oportunidade de moralizar o processo de seleção de aluno.

O Enem, logo nos primeiros anos posteriores à sua instituição, passaria a constituir uma das principais alternativas ao vestibular, sobretudo porque se tratava de uma inovação que bem se alinhava às novas diretrizes curriculares do ensino médio e às orientações da Constituição Federal e da Lei de Diretrizes e Bases da Educação. Logo após a sua instituição, foram crescentes as adesões ao ENEM por parte das instituições de ensino superior, e isso o consolidava, dia após dia, edição após edição, atingindo a dimensão atual, como veremos mais adiante.

Acompanhando o aumento do ENEM, e também buscando impulsioná-lo, o governo foi desenvolvendo diversos programas de acesso ao ensino superior, cuja sistemática utiliza a nota obtida no Exame. Assim, atualmente, com a nota do exame, o candidato pode concorrer, por meio do programa Universidade para Todos (ProUni), às vagas oferecidas por meio de bolsas de estudo integrais ou parciais em instituições particulares de educação superior; ou concorrer, com a mesma nota obtida no exame, por meio do Sistema de Seleção Unificada (Sisu), às vagas oferecidas em instituições públicas de ensino superior. O resultado do exame também é utilizado como requisito de seleção para receber o benefício do Fundo de Financiamento Estudantil (Fies), dentre outros programas. 
Essa realidade, que se espalhou por todo o País, chegou à Universidade do Estado do Rio Grande do Norte (UERN). O processo de seleção para o acesso aos cursos de graduação da UERN passou, com a instituição do Enem, a utilizar, facultativamente, a nota conjugada do Processo de Seleção Vocacionado (PSV) e do Enem; em seguida, com a adesão ao Sisu, em 2015, partes das vagas foram preenchidas pelo PSV, e a outra parte pelo Sisu; e, finalmente, a partir de 2016, todas as vagas dos cursos de graduação da UERN serão preenchidas apenas por meio do Sisu, com base na nota do Enem. Segundo matérias dos jornais locais ${ }^{1}$, durante o democrático processo de discussão com a comunidade, os dirigentes da Universidade deixaram claro que a adesão ao Exame estaria ligada diretamente à questão financeira, apesar de o foco ser na possibilidade de propiciar processos mais democráticos de acesso ao ensino superior. Portanto, a UERN adere ao ENEM/SISU anunciando o processo democrático de construção da adesão, ouvindo toda a comunidade, e a possibilidade de democratização do acesso aos seus cursos, já que possibilitaria condições mais justas e iguais entre os concorrentes.

Diante disso, este artigo analisa o processo de adesão da Universidade do Estado do Rio Grande do Norte (UERN) ao Exame Nacional do Ensino Médio e ao Sistema de Seleção Unificada (Sisu) para seleção de candidatos aos seus cursos de graduação, objetivando perceber a democratização do acesso à educação superior, tida como referendadas na expansão de vagas, na facilitação da inscrição, na possibilidade de universalização e de condições mais justas e iguais no acesso aos cursos de graduação oferecidos pela UERN. Como referência para este estudo, pensamos democracia/democratização com as concepções de Martin Trow, como apresentado por Ristoff (2014). Os dados sobre o Enem, o Sisu e o processo de adesão da UERN foram obtidos de pesquisas a notícias e reportagens veiculadas no portal do INEP, do SISU, do ENEM e da UERN, principalmente.

\section{CONTEXTUALIZANDO O ENEM}

A Constituição Federal de 1988 eleva a educação à condição de direito fundamental, indispensável à manutenção da dignidade humana de todo indivíduo. Assim como a saúde, a alimentação, a moradia, a segurança e outros, a educação é um direito social fundamental (artigo 6 o, caput, da (F), sem a qual nem as pessoas nem o próprio Estado poderão trilhar perspectiva de crescimento e desenvolvimento

Todos têm direito à educação, a qual será promovida e incentivada, de forma permanente, pelo Estado, pela família e por toda a sociedade (CF, art. 205). O dever do Estado de promover a educação se estende da educação infantil aos níveis mais elevados do ensino. Ao Estado compete promover o acesso aos níveis mais elevados do ensino, da pesquisa e da criação artística, segundo a capacidade de cada um (CF, art. 208, V). Os sistemas de ensino da União, dos Estados, do Distrito Federal e dos Municípios são organizados de forma colaborativa, de modo a assegurar a universalização do ensino obrigatório ( $C F$, art. 211, caput e $\S 4$ ). Assim é competência da união, dos Estados e do Distrito Federal legislar sobre educação e ensino, mas é reservado, privativamente, à União legislar sobre as diretrizes e bases da educação nacional com intuito de instituir o plano nacional de educação.

\footnotetext{
${ }^{1}$ Ver Jornal 'De fato' de 22/05/2014 e 'O mossoroense' de 21/05/2014.
} 
Com base no comando constitucional, é instituída a Lei 9.394, de 20 de dezembro de 1996, que estabelece as diretrizes e bases da educação nacional. A educação escolar compõe-se de dois níveis: a educação básica e a educação superior. A educação básica é formada pela educação infantil, pelo ensino fundamental e pelo ensino médio. "A educação básica tem por finalidades desenvolver o educando, assegurar-lhe a formação comum indispensável para o exercício da cidadania e fornecer-lhe meios para progredir no trabalho e em estudos posteriores" (art. 22 da LDB). A educação superior abrange diversos cursos e programas, como graduação, mestrado e doutorado, cursos sequenciais e de extensão (art. 44, I a IV, da LDB). A porta de entrada para a educação superior é a graduação, aberta a candidatos que tenham concluído o ensino médio ou programa de estudo equivalente e tenham sido classificados em processo seletivo (art. 44, II, da LDB).

Antes mesmo da instituição do Enem, a Lei de Diretrizes e Bases da Educação (LDB), Lei 9.394, de 20 de dezembro de 1996, já acabara com a obrigatoriedade do vestibular, ao dispor, em seu art. 51, acerca da autonomia das instituições de educação superior para deliberar sobre critérios e normas de seleção e admissão de seus alunos. Com base nesse permissivo legal, o fim da obrigatoriedade do vestibular levou à multiplicidade de novas formas de seleção de alunos não muito plurais, tampouco éticas: houve instituições particulares de ensino superior que passaram a aceitar cartas de recomendação de empresas no ingresso de alunos; outras definiram como critério de seleção e admissão o histórico escolar do ensino médio; houve ainda instituições que chegaram a reservar vagas para alunos de colégios conveniados. Esse contexto fez com que o Enem se transformasse, nos anos seguintes a sua instituição, numa das principais alternativas ao vestibular, sobretudo porque se tratava de uma inovação que bem se alinhava às novas diretrizes curriculares do ensino médio e às orientações da Lei de Diretrizes e Bases da Educação.

O Exame Nacional do Ensino Médio (Enem) foi instituído em 1998, por meio da Portaria no 438, de 28 de maio de 1998, do Ministério de Estado da Educação e do Desporto. No mesmo ano em que fora instituído, o Enem experimentou sua primeira edição, sendo muito bem avaliado por diversas instituições de ensino superior, que logo demonstraram a possibilidade e o interesse em adotá-lo como alternativa ao vestibular, ou pelo menos como parte da nota necessária para ingresso de alunos ao ensino superior, embora a utilização do Enem não fosse obrigatória. Assim, logo nos anos seguintes à primeira edição, diversas instituições de ensino superior passaram a adotar a nota do Enem como meio de ingresso, e o número de instituições que aderiram a essa nova alternativa foi crescente dia após dia.

Em sua página na internet, em matéria do dia 18 de junho 1999, o Inep divulgava uma lista com os nomes de 25 universidades que confirmavam o uso dos resultados do Enem como um dos critérios de acesso ao ensino superior.

Nesse processo de adesão, a PUC do Rio de Janeiro saiu na frente, destinando $20 \%$ das vagas abertas em 1999 para alunos que alcançaram mais de 70\% de aproveitamento no Exame. A Universidade do Grande $A B C$ (UniABC), de São Caetano do Sul (SP), foi mais ousada, ao comunicar ao Inep sobre a substituição do vestibular do ano 2000 pelos resultados do Enem de 1999, tornando-se, assim, a primeira instituição de ensino superior do país a decretar o fim do 
vestibular. Os critérios referentes à utilização da nota do Enem na seleção de ingresso variavam de instituição para instituição.

Já em 8 de novembro de 1999, o Inep divulgava uma nova lista de adesões ao Enem: a lista de 25 adesões do dia 18 de junho crescera para 87 adesões, das quais 12 eram de instituições públicas, e 75 de instituições privadas. Em 14 de dezembro de 1999, o número já chegava a 93 adesões. Em 29 de Agosto de 2002, em todo País, o número de adesões se ampliara consideravelmente: 338 instituições de ensino superior comunicaram ao Inep acerca da utilização do Enem em seus vestibulares. Dois anos depois, em 14 de maio de 2004, o Enem já estava presente nos vestibulares de $21 \%$ das instituições de ensino superior do Brasil. Dos 2.084 estabelecimentos de ensino superior existente no país à época, 436 haviam demonstrado o interesse na utilização dos resultados da avaliação como critério de seleção: 54 instituições públicas e 382 particulares.

Rapidamente o Enem se consolidava como uma nova forma de seleção de alunos ao ensino superior. $E$ as crescentes e rápidas adesões ao Enem por instituições de ensino superior em todo o país, logo após sua primeira edição, em 1998, foram determinantes para incentivar a participação dos alunos no exame. Desde a primeira edição, ano após ano, o número de inscritos e de participantes no Enem foi cada vez maior. E esse grande sucesso experimentado pelo exame ao longo de todos esses anos se deve, em primeiro lugar, às adesões ao resultado do Enem em complementação ou em substituição ao vestibular propostas por diversas instituições de ensino superior de todo o país.

Segundo o portal do Inep, em matéria divulgada no dia 16 de dezembro de 1998, a primeira edição do Enem, aplicada no dia 30 de agosto do mesmo ano, em 184 municípios, incluindo todas as capitais, contou com a participação de 115.575 alunos concluintes e egressos do ensino médio, de um total de 157.221 inscritos. Na segunda edição do exame, realizado no dia 29 de agosto de 1999, em 162 municípios, incluídas todas as capitais, e em 282 locais de provas, conforme matéria publicada no dia 14 de dezembro do mesmo ano, o número de participantes, em comparação com a primeira edição, mais que dobrou, saltando para 315.960 alunos, de um total de 346.953 inscritos. A abstenção (9\%), por sua vez, foi bem abaixo da registrada no primeiro exame $(26,5 \%)$.

A oitava edição (Enem 2005), aplicada em 4.375 locais de prova, distribuídos em 730 municípios, das 27 unidades da Federação, conforme matéria publicada no dia 30 de dezembro de 2005, contou com a participação de cerca de 2,2 milhões de candidatos, número que corresponde a $74,79 \%$ dos 3.004 .491 de inscritos. O crescimento considerável do número de inscritos no Enem 2005 em relação às edições anteriores do exame deveu-se ao Programa Universidade para Todos (ProUni), do Ministério da Educação, que utiliza os resultados do Enem como um dos critérios para selecionar os contemplados com bolsas de estudo integrais ou parciais em instituições privadas de ensino superior.

A edição de 2010 do Enem apresentou um salto ainda maior: conforme matéria do dia 05 de novembro de 2010, mais de 4,6 milhões de pessoas se inscreveram para fazer o exame, que foi aplicado em cerca de 16 mil localidades, distribuídas em cerca de 1.800 municípios de todos os estados brasileiras. Além da oportunidade de utilização do resultado do Enem 2010 para 
concorrer às bolsas do Programa Universidade para Todos (ProUni), havia agora também a oportunidade de utilizar o mesmo resultado do exame para concorrer às vagas oferecidas pelo Sistema de Seleção Unificada (Sisu).

Em 2015, o leque de possibilidades de estudo a partir do resultado do Enem se ampliou, graças aos implementos de novas políticas públicas de educação. E isso fez com que o número de inscrições no exame fosse ainda maior: conforme matéria divulgada em 20 de outubro de 2015, mais de 7,7 milhões de pessoas se inscreveram para fazer o exame, dos quais $78 \%$ efetivamente realizaram a prova.

Atualmente, com a nota do exame, o candidato pode concorrer, por meio do programa Universidade para Todos (ProUni), às vagas oferecidas por meio de bolsas de estudo integrais ou parciais em instituições particulares de educação superior; ou concorrer, com a mesma nota obtida no exame, por meio do Sistema de Seleção Unificada (Sisu), às vagas oferecidas em instituições públicas de ensino superior. O resultado do exame também é utilizado como requisito de seleção para receber o benefício do Fundo de Financiamento Estudantil (Fies) dentre outros programas.

As adesões ao Enem inegavelmente tornaram o acesso ao ensino superior mais cômodo e democrático, ao permitir que o mesmo resultado do exame fosse utilizado para concorrer às vagas oferecidas por diversas instituições de ensino, em qualquer local do país. Tudo isso revela a importância do Enem como instrumento de seleção para a distribuição das políticas públicas de educação

\section{DO PSV AO SISU: A ADESÃO DA UERN}

Desde sua instituição, em 1998, até o momento presente, centenas de instituições passaram a aderir ao Enem, inicialmente como complementação ao vestibular, depois em sua substituição. Com a UERN não se deu diferente: primeiro a Universidade, de forma modesta, passou a aproveitar a nota do Exame, de forma facultativa, em complementação à do Processo Seletivo Vocacionado (PSV), até passar a substituir totalmente, a partir de 2016, o PSV pelos resultados do Enem.

Antes do PSV, a UERN adotava o vestibular. Em verdade, o vestibular era uma realidade da época em que a Universidade se chamava Universidade Regional do Rio Grande do Norte (URRN). Com a mudança da denominação, em 1999, para Universidade do Estado do Rio Grande do Norte (UERN), o vestibular foi substituído, em 2000, pelo PSV. No vestibular, os candidatos participam de provas que abordam todas as disciplinas; por outro lado, no PSV, as provas são constituídas de grupos de disciplinas afins aos cursos ofertados.

Posteriormente, a UERN passou a adotar um sistema no qual a classificação de candidatos para o acesso aos cursos de graduação da UERN - para preenchimento de vagas iniciais autorizadas pelo Conselho de Ensino, Pesquisa e Extensão (CONSEPE) - faz-se a) ou por meio do 
PSV, de forma isolada; b) ou por meio do PSV combinado com o Exame Nacional do Ensino Médio (Enem).

A escolha da modalidade isolada ou combinada é feita pelo candidato, no ato de inscrição. Assim, ao efetivar sua solicitação de inscrição, o candidato fará opção por uma das seguintes modalidades: ou pelo PSV, equivalente a $100 \%$ do total de pontos; ou pelo PSV, equivalente a $80 \%$, combinado com o ENEM, equivalente a $20 \%$ do total de pontos.

O sistema acima descrito teve sua última aplicação no processo de seleção para preenchimento das vagas iniciais dos cursos de graduação da UERN no ano letivo de 2014. Essa sistemática foi substituída por uma nova sistemática, em que não é mais obrigatória a realização do PSV para concorrer às vagas ofertadas, como foi exigido até o Edital no 13/2013 para o PSV 2014. Assim, no processo de preenchimento das vagas iniciais dos cursos de graduação da UERN no ano letivo de 2015, o candidato não mais pôde combinar a nota do Enem com a do PSV: ou utilizava só a do PSV, ou somente a do Enem. Nessa nova sistemática, decorrente da adesão da UERN ao Sisu, materializada pelo Edital no 13/2014 (COMPERVE), para o Processo Seletivo de Vagas Iniciais (PSVI), 40\% (quarenta por cento) das vagas iniciais para o ano letivo de 2015 foram preenchidas por meio PSV, e 60\% (sessenta por cento) por meio do sistema Enem/Sisu. Quanto ao PSV, para preenchimento de $40 \%$ (quarenta por cento) das vagas iniciais para o ano letivo de 2015, segue as mesmas regras que expusemos acima, iguais as constantes do Edital 15/2003 (COMPERVE).

A adesão da UERN ao Sistema de Seleção Unificada (Sisu) foi realizada em 05 de dezembro de 2014, por ato do Magnífico Reitor, o Sr. Pedro Fernandes Ribeiro Neto. Tal adesão, que representa o objetivo da Universidade em utilizar a nota do Enem, por meio da plataforma do Sisu, para o preenchimento de suas vagas de graduação a partir do ano letivo de 2015, foi formalizada pela assinatura do Termo de Adesão (1 1 edição de 2015), da Secretaria de Educação Superior (SESU) do Ministério da Educação (MEC).

A adesão da UERN ao Sisu não foi integral, haja vista que 25 (vinte e cinco) cursos da UERN não participaram do Sisu em 2015, representando um total de 865 vagas que foram preenchidas pelo velho sistema do PSV. A destinação de $60 \%$ (sessenta por cento) das vagas para seleção por meio do sistema Enem/Sisu representa uma transição para a oferta de $100 \%$ (cem por cento) das vagas apenas pelo sistema Enem/Sisu. A adesão integral da UERN ao Sisu, que provavelmente ocorrerá em breve, representará o fim da utilização do Sistema de Seleção Vocacionada (PSV) para o preenchimento das vagas de graduação da Universidade.

3.1. Princípio democrático, desigualdade educacional e o elitismo do sistema de acesso ao ensino superior no brasil

O Brasil é uma República Federativa, constituída em Estado Democrático de Direito (art. 1 을 caput, da CF), que tem como objetivos fundamentais construir uma sociedade livre, justa e solidária, promovendo o bem de todos, sem preconceitos de origem, raça, sexo, cor, idade e quaisquer outras formas de discriminação, de forma a erradicar a pobreza e a marginalização e 
reduzir as desigualdades sociais e regionais, com vista a garantir o desenvolvimento nacional (art. 3ㅇ, I a IV, da CF). Todos esses objetivos fundamentais constituem valores que devem orientar 0 Estado brasileiro em todas as suas ações, e decorrem diretamente do princípio democrático.

O princípio democrático, que perpassa toda a Constituição Federal, nutre as ações públicas de valores como justiça, equidade e solidariedade. O Estado brasileiro apresenta grande desigualdade social e regional, e isso tem essencial explicação histórica e se deve, sobremaneira, à vasta dimensão territorial. Mais do que apenas e meramente econômica, a desigualdade social e regional reflete também e inevitavelmente no aspecto educacional: é profunda a desigualdade educacional entre brancos e negros, entre ricos e pobres, entre os que moram no campo e na cidade, entre os que moram no Norte e no Sul. Por questões de cor, de classe econômica e de localização geográfica, ainda é grande a desigualdade educacional no país. E é justamente por isso que o legislador constituinte de 1988 incutiu na Constituição Federal a necessidade de se promover o bem de todos, sem preconceitos de qualquer natureza, segundo os valores de justiça e solidariedade, pois sem isso não há formas de se combater a imensa desigualdade social e regional existente no Brasil - problema de cuja solução depende o desenvolvimento nacional.

O problema educacional brasileiro não é, pois, episódico, mas decorre da própria construção histórica do país, marcada pela desigualdade social e regional. Por muito tempo houve a centralização da educação nos grandes centros, restrita às classes sociais mais abastadas. Promover o desenvolvimento educacional, com vista a expandir seu acesso a todos, estava fora das prioridades dos governos que dirigiram o Brasil nesses mais de 500 anos. Educação sempre foi um direito de poucos, em outras palavras, sempre existiu no Brasil um sistema elitista de acesso ao ensino superior. O sistema de educação superior é elitista pois permite acesso apenas para até $15 \%$ dos jovens em idade apropriada (TROW apud RISTOFF, 2014).

Mas esse quadro histórico começa a mudar, sobretudo nas últimas duas décadas, momento em que se percebe uma nítida e continuada implementação de políticas públicas educacionais expansionistas e universais, voltadas, efetivamente, para melhorar a educação superior no País. Nesse período, "a educação superior brasileira foi marcada por forte expansão sob todos os aspectos: cresceu o número de instituições, de cursos, de vagas, de ingressantes, de matrículas e de concluintes" (RISTOFF, 2014).

Foi um crescimento constante e significativo, com marcada aceleração de ritmo de 1999 a 2003, durante o segundo mandato do governo Fernando Henrique Cardoso - período em que observamos altas taxas de crescimento da educação superior, notadamente em função da proliferação de instituições privadas, muitas delas, e.g. Centros Universitários e Universidades, dotados de autonomia para criar novos cursos e aumentar o número de vagas ofertadas. Nos doze anos dos governos Lula-Dilma, o crescimento se manteve constante, embora em ritmo mais moderado, e mais em sintonia com as políticas globais de inclusão social, passando a expansão a estar visceralmente associada à democratização do campus brasileiro e orientada por um conjunto de políticas estruturantes implantadas nos últimos anos (RISTOFF, 2014).

Todo esse crescimento se dá, portanto, em momento posterior à Constituição Federal de 1988. A própria Constituição Federal foi redigida com um viés prospectivo quanto ao futuro da 
educação brasileira, o que reflete a preocupação do legislador Constituinte com a situação calamitosa da educação no País. Isso, no entanto, revela que o Brasil já tenha atingido um sistema de educação superior de massas, deixando para trás o sistema elitista, que privilegiava alguns poucos indivíduos das classes mais favorecidas economicamente? Para responder a essa pergunta, entendamos primeiramente o que é o sistema elitista, o sistema de massa e o sistema universal, nos termos preconizados por Martin Trow.

Segundo a classificação proposta por Martin Trow, o sistema de educação superior em um determinado país pode encontrar-se em um destes três níveis de desenvolvimento: o sistema elitista, o sistema de massa e o sistema universal. Para Trow, um sistema de educação superior é considerado de elite, elitista, se nesse sistema de educação o acesso ao ensino superior abrange aproximadamente até $15 \%$ dos jovens de idade apropriada. Em outras palavras, se em um determinado país, da totalidade dos jovens em idade apropriada para ingressar na universidade, apenas $15 \%$ ou menos desses jovens tem acesso ao ensino superior, então vigora nesse país um sistema elitista de acesso ao ensino superior. Se, por sua vez, o percentual de acesso desses jovens encontra-se entre $16 \%$ e $50 \%$, o sistema de educação superior é considerado de massa. Assim, o sistema de massas se consolida quando atingi 30\% de acesso. Por fim, a partir de 50\%, o sistema de acesso ao ensino superior é considerado universal (TROW apud RISTOFF, 2014).

No Brasil, não obstante o salto que a educação superior tenha dado de 1990 à atualidade, ainda vige um sistema de acesso ao ensino superior basicamente elitista. Muito melhoramos, em termos de expansão da educação superior, nesse período de mais de 20 anos que precedeu a Constituição Federal de 1988 e no qual se consolidou a Democracia brasileira, mais ainda continua a vigorar no Brasil o elitismo do sistema de acesso ao ensino superior. Felizmente, podemos ser otimistas e acreditar que vivemos um período de transição, em que sairemos do tradicional modelo elitista para incorporar um sistema de massa. O Brasil "começa apenas a querer sair de um sistema de acesso de elite", pois "para consolidar um sistema de massas o Brasil precisa pelo menos atingir a meta de 33\% recentemente aprovada, no novo Plano Nacional de Educação (PNE), para o ano 2024" (TROW apud RISTOFF, 2014).

3.2. A democratização do acesso ao ensino superior promovida pela UERN: uma análise à luz da adesão ao ENEM/SISU

Consideramos democrático um sistema de massa ou universal de acesso ao ensino superior, nos termos que acima apresentamos, segundo a classificação proposta por Martin Trow. E mais que isso, um sistema que promova uma isonomia efetiva de oportunidades de acesso a todos aqueles que desejam ingressar no ensino superior. Entendamos por efetiva isonomia aquela que se filia aos processos históricos de exclusão de determinadas classes sociais e busca compensá-la. Eu outras palavras, um sistema verdadeiramente democrático de acesso ao ensino superior é aquele que vai além da mera igualdade formal, privilegiando a igualdade material, o que significa reconhecer a desigualdade existente entre os sujeitos de uma sociedade, a fim de dar tratamento especial aos menos favorecidos para que efetivamente possam usufruir em iguais condições com os mais favorecidos. Dar um tratamento verdadeiramente isonômico 
"significa tratar igualmente os iguais e desigualmente os desiguais, na exata medida de suas desigualdades" (NERY JUNIOR, 1999, p. 42).

Nesse contexto, democratizar o acesso ao ensino superior é criar mecanismos que possibilitem e facilitem o ingresso no ensino superior, de forma a contemplar todos os indivíduos, independentemente de sexo, cor, condição econômica, localização geográfica etc. Isso não pode ser diferente porque, sendo o Brasil uma República Federativa, constituída em Estado Democrático de Direito (art. 1ํ, caput, da CF), tem valores democráticos que devem ser protegidos. Tanto é que o Brasil tem como objetivos fundamentais construir uma sociedade livre, justa e solidária, promovendo o bem de todos, sem preconceitos de origem, raça, sexo, cor, idade e quaisquer outras formas de discriminação, de forma a erradicar a pobreza e a marginalização e reduzir as desigualdades sociais e regionais, com vista a garantir o desenvolvimento nacional (art. 3ㅇ, I a IV, da CF). Assim, no contexto da educação, promover mecanismos que possibilitem e facilitem o acesso de todos ao ensino superior constitui também, de forma reflexa, um objetivo fundamental a ser perseguido e fomentado pelo Estado brasileiro.

Os mecanismos seletivos da educação superior não podem se desvincular do contexto histórico-social da realidade Brasileira, que é marcada por forte preconceito e exclusão contra negros e pobres, que apresenta imensa desigualdade econômica e educacional, que sempre foi marcado pelo elitismo do sistema de acesso à universidade. É preciso ter-se em mente que o Brasil é um país de grandes contrastes, especialmente culturais e econômicos, que impactam fortemente na distribuição das oportunidades de mercado e de educação. Dessa forma, é imprescindível, para que conquistemos um sistema de massa e verdadeiramente democrático, que busquemos desenvolver mecanismos que possam possibilitar aos negros e aos pobres conquistar vagas nas universidades. Felizmente, nas duas últimas décadas, após a promulgação da Carta Cidadã, tais mecanismos foram sendo paulatinamente criados, possibilitando um salto sem precedentes na história da educação superior no Brasil.

Da promulgação da Constituição Federal de 1988 para cá - orgulhemo-nos de enfatizar -, diversas instituições de ensino superior foram criadas, tanto federais, quanto estaduais e municipais, tanto públicas, quanto privadas; o número de vagas e de cursos cresceu múltiplas vezes mais; as universidades chegaram ao interior, em diversas regiões afastadas dos grandes centros; foram criados o Enem, o ProUni, o FIES, o Sisu e diversos outros programas de facilitação ao acesso ao ensino superior; cotas para negros, cotas para alunos de escolas públicas, cotas para deficientes etc. Todos esses mecanismos foram criados com a nítida finalidade de fazer com que a classe menos favorecida da sociedade pudesse ocupar os bancos das universidades públicas e privadas do País, de forma a desvincular o acesso ao ensino superior da capacidade econômica. Educação é direito de todos, e esse direito só pode ser objetivamente usufruído se for possível alcançá-lo diretamente, sem tantas barreiras de ordem econômica, estrutural e geográfica. Não basta somente exaltar a existência de um direito, é preciso criar a ponte de acesso a ele - é o que tem sido feito nos ótimos anos, felizmente. O Brasil trila o caminho da democratização do acesso ao ensino superior, vivendo, nesse contexto, um memento de transição de um sistema elitista para um sistema de massa da educação superior.

Em contexto regional - voltando agora os olhos para o Estado do Rio Grande do Norte -, as engrenagens também giram em consonância com essa mesma ideia, de democratizar o acesso 
ao ensino superior. $E$ isso se percebe em vários contextos. A própria decisão de implantar o Campus Central da UERN no Município de Mossoró é uma decisão consonante com a democratização do acesso ao ensino superior, por permitir uma descentralização dos campi universitários da capital e da região metropolitana. Com a implantação da UERN em Mossoró, a população do oeste potiguar pôde ingressar no ensino superior sem ter que se deslocar para a capital - algo que constitui uma façanha hoje, quiçá em outrora. As universidades concentradas nas capitais do País criavam, para as pessoas do interior, uma dificuldade geográfica e econômica de ingresso no ensino superior.

Com a instituição da UERN em Mossoró, pois, as pessoas do oeste potiguar puderam ingressar na universidade com mais facilidade. A situação da educação superior do interior potiguar melhorou ainda mais com a criação de diversos campis da UERN em localidades estratégicas, como o Campus Avançado de Assu, o Campus Avançado de Pau dos Ferros, o Campus Avançado de Patu e o Campus do Seridó, em Caicó, sem falar da criação, em 2002, do Programa de Interiorização da UERN, com a instalação dos Núcleos de Educação Superior. A questão geográfica de centralização das universidades nas capitais, portanto, é um problema que dificulta o acesso ao ensino superior por parte daqueles que moram em munícipios afastados no interior; problema que, no exemplo potiguar, teve a UERN como primeiro e principal mecanismo saneador.

Mas a contribuição da UERN com a democratização do acesso ao ensino superior na região potiguar não se limita ao aspecto geográfico, com a instalação do Campus Central em Mossoró e a distribuição de campi nos munícipios de Assu, Pau dos Ferros, Patu e Caicó. A UERN também tem promovido a democratização do acesso ao ensino superior por meio de diversos mecanismos de natureza sociocultural e econômica, criando maior oportunidade de acesso aos seus cursos de graduação aos estudantes de famílias mais pobres e portadores de deficiência. Assim, em cumprimento à Lei Estadual no 8.258, de 27 de dezembro de 2002, que trata da reserva social de vagas, a UERN oferta $50 \%$ (cinquenta por cento) das vagas iniciais distribuídas por campus, núcleos, cursos, habilitação, turno e semestre letivo aos alunos que tenham cursado integralmente o ensino fundamental e médio em escola pública ${ }^{2}$. A reserva de metades das vagas para alunos oriundos de escolas públicas cumpre uma importante função social de democratização do acesso ao ensino superior, pois esses alunos, por não terem tido oportunidades de uma formação educacional básica de qualidade - é inquestionável que a educação pública no Brasil está muito aquém dos padrões de qualidade desejados e que são ofertados nas instituições de ensino privadas -, estão em grande desvantagem na disputa, com os alunos oriundos de escolas privadas, por uma vaga na universidade. A reserva social de vagas, dessa forma, constitui um ativismo jurídico importante de promoção de oportunidade de acesso ao ensino superior por parte daqueles que não têm condições de pagar por uma formação educacional inicial de qualidade. Reservar parte das vagas e permitir que estudantes de escolas públicas concorram entre si por uma vaga na universidade é uma importante medida de democratização do acesso ao ensino superior, por permitir uma igualdade material do direito de ir à universidade. Iguais considerações são estendidas à reserva de vagas para pessoas com deficiência, em atendimento à Lei Estadual no 9.696, de 25 de fevereiro de 2013, combinada com

\footnotetext{
${ }^{2}$ Edital no 15/2013 - COMPERVE e Edital no 13/2014 - COMPERVE.
} 
a disposição do artigo 5으 do Decreto no 5.296, de 2 de dezembro de 2004, que destina 5\% (cinco por cento) das vagas iniciais - distribuídas por campus, curso, habilitação, turno e semestre letivo da UERN - a candidatos, exclusivamente, com deficiência comprovada por profissional cadastrado pelo Sistema Único de Saúde (SUS).

Feitas essas considerações iniciais, que demonstram a importante atuação da UERN na promoção da democratização do acesso ao ensino superior no oeste potiguar, pergunta-se: e quanto à adesão, em 2015, da UERN ao Sistema de Seleção Unificada, haverá alguma contribuição no sentido de facilitar o acesso aos cursos de graduação da Universidade, de forma a fomentar a democratização, em algum aspecto, do acesso ao ensino superior no meio oeste potiguar? É uma reflexão feita em futuro do presente porque ainda é um passo novo dado pela UERN - a adesão se deu em 2015 e ainda não há dados sobre que se valer em análise-, cuja resposta ora será dada segundo um olhar prospectivo, à luz do que se observa da experiência nacional e de acordo com o que se sabe do contexto regional e local onde se situa a instituição de ensino superior e das pessoas que buscam as oportunidades de se graduarem, não obstante as dificuldades por que passam no meio em que vivem.

A adesão da UERN ao Sistema de Seleção Unificada (Sisu) foi realizada em 05 de dezembro de 2014, pela assinatura do Termo de Adesão (1a edição de 2015), da Secretaria de Educação Superior (SESU) do Ministério da Educação (MEC). Com essa adesão, a Universidade manifestou seu desejo de utilizar a nota do Enem, por maio da plataforma do Sisu, para selecionar candidatos ao preenchimento de suas vagas de graduação. Essa nova sistemática de seleção já foi experimentada em 2015, mais ainda de forma parcial: conforme o Edital no 13/2014 (COMPERVE), 40\% (quarenta por cento) das vagas iniciais para o ano letivo de 2015 foram preenchidas por meio do PSV, e 60\% (sessenta por cento) por meio do Sistema de Seleção Unificada. Contudo, nos anos posteriores, a expectativa é a de que seja utilizado o Sisu para selecionar candidatos à totalidade das vagas, mantendo-se a sistemática do sistema de cotas raciais e para portadores de deficiência, conforme imposição de lei estadual. A adesão integral da UERN ao Sisu representará o fim da utilização do Sistema de Seleção Vocacionada (PSV) para o preenchimento das vagas de graduação da Universidade.

Essa adesão constitui um passo importante em termos de promoção do acesso aos cursos de graduação da Universidade, contribuindo para fomentar a democratização do acesso ao ensino superior no meio oeste potiguar, assim como tem sido de uma forma geral, à semelhança da experiência nacional. Vale dizer, a princípio, que a maioria esmagadora das pessoas que têm pretensões às vagas de graduação da UERN - alunos de Mossoró, Assu, Patu, Caicó e cidades próximas, inclusive do Ceará - sequer têm condições de pagar o preço do PSV. O custo financeiro - não podemos negar - é umas das barreiras de acesso ao ensino superior a ser considerada. Com a adesão ao Sisu, o aluno somente terá que fazer o Enem, que é gratuito (para os de insuficiência financeira, como é o caso do público aqui considerado), sem inclusive ter que desembolsar os gastos com deslocamento para fazer participar do PSV nos campi, uma vez que o Enem é realizado em cada cidade. Dessa forma, um estudante dos municípios cearenses de Russas, Limoeiro do Norte, Quixeré, por exemplo, de onde é grande o fluxo para a UERN, poderá fazer o Enem em sua cidade e concorrer a uma vaga na UERN sem precisar realizar qualquer gasto e deslocamento. É preciso ter sensibilidade para perceber que um recém-concludente do 
ensino médio, apesar de um bom aluno, não consegue chegar à universidade porque não encontra de onde tirar recursos para custear os gastos referentes à participação em um vestibular - é a realidade do Brasil, infelizmente!

No PSV, na fase de inscrição, previamente o candidato deve escolher o curso em que pretende graduar-se, caso passe na seleção, e concorrerá às vagas da opção que escolher, apenas. Em outras palavras, se optou pelo Curso de Medicina, por exemplo, cuja nota de corte geralmente é a mais elevada, não assumirá uma vaga na UERN para cursar Medicina se não atingir o limite de pontos satisfatório no PSV para as vagas referentes a esse curso, tampouco assumirá qualquer outro curso da UERN, embora queira e tenha atingido pontuação suficiente para ser aprovado em qualquer outro curso ofertado. Se quiser ainda cursar Medicina ou outro curso na UERN terá que se submeter a outro processo seletivo. Vaja-se o problema: nesse contexto, o sistema seletivo barra alunos mais preparados, e seleciona alunos menos preparados! No exemplo citado, o aluno que não conseguisse atingir uma pontuação satisfatória para a vaga em Medicina, também não assumiria uma vaga em qualquer outro curso, embora, com a sua pontuação, ficasse em primeiro ou nas primeiras colocações com relação a outros cursos. Com o Sisu esse problema é corrigido, pois com a nota do Enem, o candidato, de sua casa, de um terminal de computador ligado à internet, poderá concorrer, de uma única vez, a até duas vagas, e acompanhar seu desempenho durante o período de seleção, podendo alterar suas opções. Assim, o candidato, durante a etapa de inscrição, poderá acompanhar, pelo sistema do Sisu, o seu desempenho, trocando suas opções sempre que sua nota for insuficiente. Em outros termos, o candidato poderá testar sua nota para determinado curso, como Medicina, por exemplo, e se verificar, ao longo do processo seletivo, que sua nota será insuficiente, poderá cadastrá-la para outro curso de seu interesse, quantas vezes forem necessárias, durante a fase de seleção. Ademais, o Sisu oferece duas opções de inscrição - seleção em primeira opção e seleção em segunda opção - ofertadas em períodos distintos, que permite ao candidato, não selecionado em primeira opção, a chance de, em momento posterior, concorrer às vagas remanescentes, em igual sistemática descrita para a primeira opção. Apesar de tudo isso, ainda há formação de lista de espera, para eventuais desistências de candidatos selecionados nas opções que antecederam. O Sisu, dessa forma, corrige o problema que o PSV apresentava: de deixar gente capacitada, preparada fora da universidade. O Sisu se mostra mais democrático nesse ponto porque, além de ser mais meritocrático, mostra-se mais razoável, eficiente, justo e afeto aos valores intrínsecos ao princípio democrático.

Enfim, a adesão da UERN ao Sisu constitui um passo importante em termos de promoção do acesso aos cursos de graduação da Universidade, contribuindo para fomentar a democratização do acesso ao ensino superior, porque encurta distâncias (barreiras geográficas), diminui ou acaba com os gatos (barreiras financeiras), e permite a alocação da nota durante a fase de seleção, trazendo maior facilidade, comodidade, eficiência e meritocracia ao processo de seleção de candidatos às vagas ofertadas. Pelo Sisu, a probabilidade de o candidato conquistar uma vaga aumenta substancialmente, reduzindo o problema de ter que repetir o processo seletivo e a sensação de fracasso. 


\section{CONSIDERAÇÕES FINAIS}

No Brasil, sempre vigorou um sistema elitista de acesso ao ensino superior, cuja justificativa tem raízes profundamente históricas. Esse sistema vai de encontro aos ditames do princípio democrático, que não se coaduna com essa profunda desigualdade educacional existente no País. Dessa forma, trabalhar tais questões, discuti-las em âmbito acadêmico, é uma forma de chamar a atenção de todos para a necessidade de se expandir, de se difundir o acesso ao ensino superior, contribuindo para mudar esse quadro educacional crônico, decorrente da própria construção histórica do país, marcada pela desigualdade social e regional. Para tanto, as políticas públicas educacionais devem ser implementadas com vistas a atingir o maior número possível de indivíduos, assegurando condições reais, efetivas e equitativas de acesso, capazes de amenizar as dificuldades e desigualdades socioeconômicas, históricas e culturais existentes.

Felizmente, mudanças estão ocorrendo, sobretudo nas últimas duas décadas. Graças a tais mudanças, o Brasil começa a avançar rumo a um sistema de massa no que toca ao acesso ao ensino superior, abandonando o velo modelo elitista, e isso se deve principalmente ao desenvolvimento de diversos programas educacionais e incentivos do Governo Federal. No tocante ao ensino superior, a oferta de vagas foi substancialmente ampliada e o acesso foi bastante facilitado, seja pela oferta de bolsas gratuitas totais e parciais e financiamento estudantil em universidades privadas, seja pela criação de diversas novas universidades públicas, do Sisu e do Enem. O Enem, em conjunto com outros programas do Governo Federal, como o Sisu, representa um enfrentamento contra os problemas de desigualdade educacional no Brasil, fomentando a democratização do acesso ao ensino superior.

O caráter democrático e plural do Enem/Sisu, como se demonstrou, se apresenta de suma importância como forma de enfrentar esse problema educacional brasileiro, ao possibilitar e facilitar o ingresso no ensino superior, de forma a contemplar todos os indivíduos, independentemente de sexo, cor, condição econômica, localização geográfica etc. O Enem/Sisu, nesse contexto, se apresenta como mecanismos criados com a nítida finalidade de fazer com que a classe menos favorecida da sociedade pudesse ocupar os bancos das universidades públicas e privadas do País, de forma a desvincular o acesso ao ensino superior da capacidade econômica e de questões geográficas e sociais.

No contexto da adesão da UERN ao Enem/Sisu, é perceptível a importância que isso representará para a democratização do acesso ao ensino superior no oeste potiguar, assim como tem sido de uma forma geral, à semelhança da experiência nacional. A adesão constitui um passo importante em termos de promoção do acesso aos cursos de graduação da Universidade, contribuindo para fomentar a democratização do acesso ao ensino superior, porque encurta distâncias (barreiras geográficas), diminui ou acaba com os gatos (barreiras financeiras), e permite a alocação da nota durante a fase de seleção, trazendo maior facilidade, comodidade, eficiência e meritocracia ao processo de seleção de candidatos às vagas ofertadas. 


\section{REFERÊNCIAS}

Bobbio, N. (1987). Estado, governo, sociedade: por uma teoria geral da política. Rio de Janeiro: Paz e Terra.

Bonavides, P. (1999). Ciência Política. São Paulo: Malheiros.

Brasil. (1988). Constituição da República Federativa do Brasil de 1988. Disponível em: <http://www.planalto.gov.br/ccivil_03/constituicao/ConstituicaoCompilado.htm>. Acesso em: 3 de janeiro de 2016.

- (1996). Lei no 9.394. Lei de Diretrizes Orçamentárias (LDB). Disponível em: <http://www.planalto.gov.br/ccivil_03/leis/19394.htm.ldb>. Acesso em 22 jan. 2016.

(1998). Ministério da Educação (MEC). Portaria no 438 que institui o Exame Nacional do Ensino Médio (ENEM). Disponível em: <http://www.crmariocovas.sp.gov.br/pdf/diretrizes_p0178-0181_c.pdf>. Acesso em: 22 jan. 2016.

Uern. (2013). Edital no 15/2013 - COMPERVE. PSV/2014. Disponível em: <http://www.uern.br/controledepaginas/compervenoticias/arquivos/1887edital_na_15.201 3_psv_2014_abertura_do_psv.pdf>. Acesso em: 10 abr. 2016.

. (2014). Edital no 13/2014 - COMPERVE. PSVI/2014. Disponível em: < http://www.uern.br/controledepaginas/comperve-editais-vestibular/arquivos /1876edital_na_13.2014_psvi_2015_abertura_do_psv_ok.pdf>. Acesso em: 10 abr. 2016.

BRASIL. (1998). Inep. O fim da obrigatoriedade do vestibular. Notícia publicada em 04 de dezembro de 1998. Disponível em: <http://portal.inep.gov.br/todas-notícias>. Acesso em 22 fev. 2016.

(1999). Inep. Enem substituirá vestibular da Universidade do Grande ABC. Notícia publicada em 08 de junho de 1999. Disponível em: <http://portal.inep.gov.br/todasnotícias>. Acesso em 22 fev. 2016.

(1999). Inep. Universidades têm liberdade para definir uso do Enem. Disponível em: <http://portal.inep.gov.br/todas-notícias>. Acesso em 22 fev. 2016.

. (1999). Inep. Enem já é aceito por 87 instituições de ensino superior. Disponível em: <http://portal.inep.gov.br/todas-notícias>. Acesso em 22 fev. 2016.

(1999). Inep. Exame contou com a presença de 91\% dos inscritos. Disponível em: <http://portal.inep.gov.br/todas-notícias>. Acesso em 22 fev. 2016.

(1999). Inep. Resultados do Enem serão aceitos por 93 instituições de ensino. Disponível em: <http://portal.inep.gov.br/todas-notícias>. Acesso em 22 fev. 2016.

. (2000). Inep. Disponível em: <http://portal.inep.gov.br/todas-notícias>. Acesso em 22 fev. 2016.

. (2003) Inep. Número de inscritos no Enem 2003 é de quase 1,9 milhão. Disponível em: <http://portal.inep.gov.br/todas-notícias>. Acesso em 22 fev. 2016. 
- (2005). Inep. Procura pelo Enem dobra em 2005. Disponível em: <http://portal.inep.gov.br/todas-notícias>. Acesso em 22 fev. 2016. . (2010). Inep. Tudo pronto para aplicação do Enem 2010. Disponível em: <http://portal.inep.gov.br/todas-notícias>. Acesso em 22 fev. 2016.

- (2013). MEC. SISU. Termo de Adesão ao Sisu da UERN. Disponível em: < http://www.uern.br/ controledepaginas/informacoes-vestibularcomperve/arquivos/194237_1417806129117_termo_adesao_1987. pdf>. Acesso em: 10 de abr. 2016.

Diniz, M. H. (1998). Dicionário Jurídico. São Paulo: Saraiva.

Nunes, P. (1993). Dicionário de Tecnologia Jurídica. Rio de Janeiro: Freitas Bastos.

Ristoff, D. (2016). O novo perfil do campus brasileiro: uma análise do perfil socioeconômico do estudante de graduação. Disponível em: <http://www.scielo.br/pdf/aval/v19n3/10.pdf>. Acesso em: 5 abr. 2016. 